\title{
Using Infrared Thermography to Study Freezing in Plants
}

\author{
Michael Wisniewski and D. Michael Glenn \\ U.S. Department of Agriculture, Agricultural Research Service, \\ Appalachian Fruit Research Station, 2217 Wiltshire Road, Kearneysville, WV 25430
}

\author{
Lawrence Gusta \\ Plant Sciences Department, Crop Development Centre, University of Saskatchewan, \\ Saskatoon, Saskatchewan, Canada S7N 5A8
}

\author{
Michael P. Fuller \\ School of Biological Sciences, University of Plymouth, Plymouth, \\ Devon, PL4 8AA, United Kingdom
}

Additional index words. ice nucleation active bacteria, supercooling, kaolin, frost protection, ice nucleation

\begin{abstract}
Factors that determine when and to what extent a plant will freeze are complex. Although thermocouples have served as the main method of monitoring the freezing process in plants, infrared (IR) thermography offers distinct advantages and the use of this latter technology has provided new insights on the processes of ice nucleation and propagation. This technology is based on the fact that freezing is an exothermic event. The temperature and spatial resolution of a high-resolution IR camera has enabled researchers to clearly define initial sites of nucleation as well as monitor the ice front as it spreads into surrounding tissues. Ice nucleation is induced by both extrinsic and intrinsic nucleators. Ice nucleation-active bacteria and moisture are two major extrinsic agents. In herbaceous plants, the influence of extrinsic ice nucleators on ice nucleation can be moderated by thick cuticles or the application of synthetic hydrophobic barriers. The situation in woody plants, however, is different. Woody plants appear to possess native, intrinsic nucleating agents that are as active as many extrinsic agents. However, the identity of the intrinsic nucleating agents in woody plants is not known. Despite the presence of intrinsic nucleating agents, barriers exist in woody plants that inhibit growth of ice from older stems into primary, lateral appendages. This is important because many tissues in woody plants that are frostsensitive are flowers and primary, elongating shoot tissues that arise from buds attached to older stems. Pictures derived from video segments of the freezing process and data on the ability to block nucleation through the use of hydrophobic kaolin are provided.
\end{abstract}

As highlighted in other presentations from this symposium, fruit crops throughout the central and southern plains, the midwest, and southeast sustained unprecedented damage as a result of a record-breaking freeze that occurred in early Apr. 2007. Although heroic efforts were made in many cases to provide frost protection, most efforts were futile. Partially to blame for this failure is our continuing lack of knowledge about what makes plants freeze at any particular temperature and what frost protection methods should be used for different freezing weather scenarios. The purpose of this presentation is to provide information on how high-resolution infrared thermography can be used to study the freezing process in plants, what we have learned from these studies, and how this has led to potential new approaches to providing frost protection. It should be noted that the ideas and concepts presented have been developed over the past 20 years through experimental investigations and through countless conversations with plant physiologists, horticulturists, and microbiologists who have devoted significant attention to the freezing process in plants. A podcast of the presentation made during this symposium is available through the ASHS website (ashs.org) in "2006-2007 HortTalks Presentations."

Received for publication 25 Jan. 2008. Accepted for publication $20 \mathrm{Feb} .2008$

${ }^{1}$ To whom reprint requests should be addressed; e-mail michael.wisniewski@ars.usda.gov
Great effort and expense are used during a frost episode to protect plant tissues that have no freezing tolerance and are killed if frozen. These efforts include plant covers, windmills to mix layers of air, smudge pots to release heat, and the spraying of copious amounts of water (Fig. 1). However, it is not generally recognized that for ice to form on or within a plant, ice nucleation must first occur. Although the melting point of ice is $0{ }^{\circ} \mathrm{C}$, the freezing temperature is not as defined (Ashworth, 1992). Although pure water has a freezing temperature of $-40{ }^{\circ} \mathrm{C}$ (homoge-

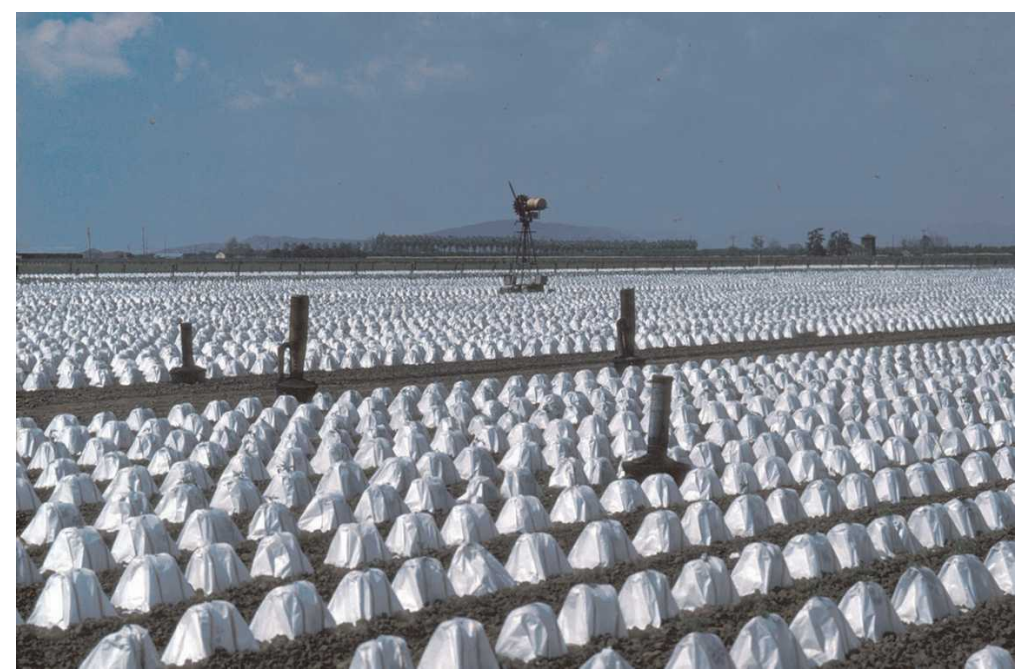

Fig. 1. Frost protection measures (plant covers, smudge pots, and windmills) used to protect tomato plants in a field in California. (Courtesy of S. Lindow.) neous nucleation temperature), freezing occurs in nature at much warmer subzero temperatures as a result of the presence of heterogenous nucleators that are very effective at inducing ice crystal formation (Franks, 1985). The role of heterogeneous ice nucleators in inducing ice formation in plants is important because if methods can be developed for regulating ice nucleation, significant advances could be made in limiting frost injury to freezing-sensitive plants (Wisniewski and Fuller, 1999). For a detailed review of this subject, see Wisniewski et al. (2002b and 

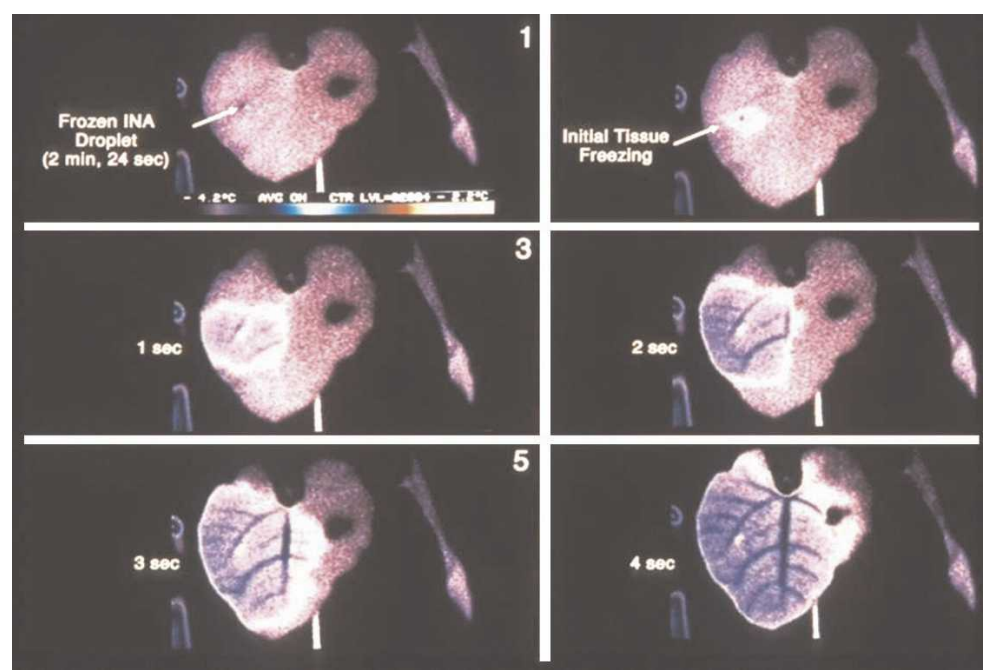

Fig. 2. Visualization of a bean plant freezing using infrared video thermography. Frozen drop of water containing ice-nucleation-active (INA) bacteria is visible in the top left frame. Freezing of plant is initiated at the site of INA bacteria and then rapidly progresses through the rest of the leaf. Dark spot on the right side of bean leaf is unfrozen water on the surface of the leaf. references within). A major question concerns the relative importance of extrinsic ice nucleation agents such as ice-nucleationactive (INA) bacteria and intrinsic nucleation agents synthesized by plants. The working hypothesis, first postulated in the early 1980s, was that by controlling extrinsic (external, nonplant-based) nucleation events, plants could supercool well below $0{ }^{\circ} \mathrm{C}$ (Lindow, 1995). However, research also revealed the presence of intrinsic (internal plant-based) nucleating agents (Ashworth and Kieft, 1995) which has made the practical application of blocking extrinsic ice nucleation problematic.

Part of the problem in trying to resolve how plants freeze is the difficulty in determining where freezing is initiated in a plant and how the freezing process is propagated. This is because until recently, the main methods of determining when ice nucleation has occurred have been through the use of thermocouples (which relies on the detection of the heat of fusion as water changes from a
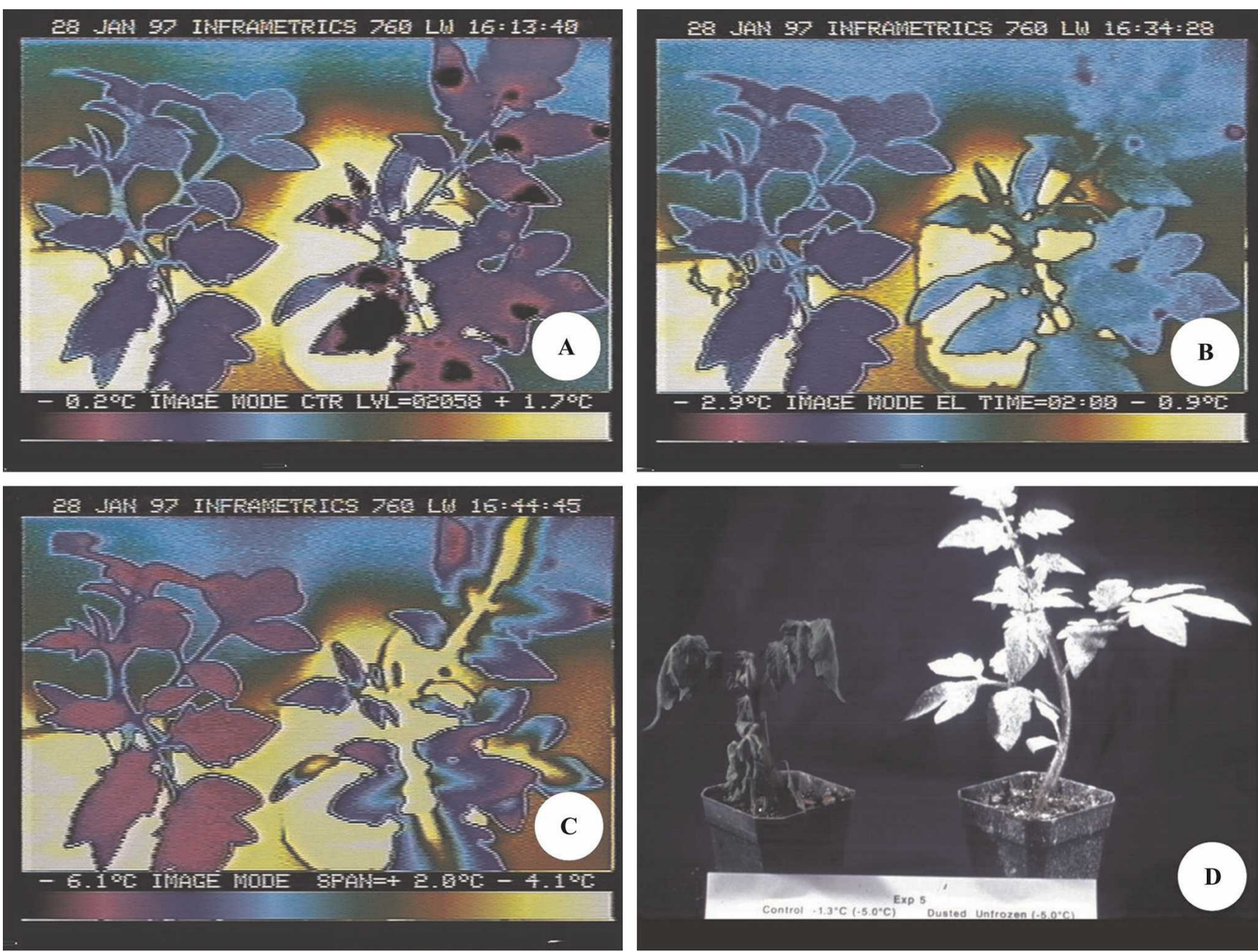

Fig. 3. Frost protection of kaolin-coated tomato plants as observed with infrared thermography. (A-C) The kaolin-coated plant is on the left and the uncoated plant is on the right. Both plants were sprayed with water containing ice-nucleation-active bacteria before being subjected to the programmed freezing event. (A) Plants are unfrozen; dark patches on coated plant (right) are areas where the leaf temperature is below $-0.2{ }^{\circ} \mathrm{C}$ (offscale). This is the result of the wet leaf surface being subject to evaporative cooling.(B) Uncoated plant (right) frozen at $\approx-2.5^{\circ} \mathrm{C}$ as evidenced by the warmer leaf temperature resulting from the heat of fusion generated during the freezing process.(C) The kaolin-coated plant (left) remained unfrozen at $-6^{\circ} \mathrm{C}$, whereas continued freezing and ice formation is evident in the uncoated plants (right), again as evidenced by the warmer leaf temperature.(D) Plants observed after removal from the environmental chamber and thawing. The uncoated plant (left) was dead, whereas the kaolin-coated plant (right) was uninjured. (Reprinted from Wisniewski et al. 2002a.) 
liquid to a solid) or simple visual inspection. Methods to determine the activity and abundance of heterogeneous nucleators have relied on the use of small portions of plant tissues or plant macerates. Wisniewski et al. (1997), however, have demonstrated the use of high-resolution infrared thermography to study the freezing process in plants. Using this technology, it is possible to determine the role of extrinsic and intrinsic ice nucleating agents in the freezing process, rates of ice propagation, the effect of plant structure on the freezing process, and how the specific pattern of freezing relates to visual patterns of injury (Ball et al., 2002; Hacker and Neuner, 2007; Wisniewski and Fuller, 1999). It has also been possible to clearly evaluate if the reduction of ice nuclei or inhibiting their activity is a feasible approach to frost protection. An illustration of this technology is presented in Figure 2.

\section{FACTORS AFFECTING EXTRINSIC ICE NUCLEATION IN PLANTS}

Perhaps the most critical factor in determining the freezing temperature of herbaceous plants is the presence or absence of surface moisture (Ashworth, 1992). Dry plants will always supercool to a lower temperature than wet plants. A second determinant is the presence or absence of ice nucleators. If INA bacteria are present, they will induce plants to freeze at a warmer temperature than just moisture alone (Fuller and Wisniewski, 1998; Wisniewski et al., 1997). The presence of nucleators on the surface without moisture is not effective because ice nucleators are only active in aqueous solutions (Wisniewski et al., 2002a, 2002b).

Wisniewski and Fuller (1999) demonstrated that for the presence of external ice (frozen moisture) on the plant surface to induce ice formation inside a plant, the ice must physically grow through a crack in the cuticle, through a broken hair cell, or through a stomatal opening. Thick cuticles, like found in many evergreen plants, serve as an effective barrier to ice nucleation (Workmaster et al., 1999). The implication of this research was that if one could effectively block the growth of external ice crystals into the interior of the plant, the plants would supercool several degrees without freezing.

\section{HYDROPHOBIC BARRIERS CAN BLOCK ICE NUCLEATION AND PROVIDE FROST PROTECTION}

Wisniewski et al. (2002a) investigated a novel approach to providing frost protection. They used a hydrophobic kaolin-based particle film to mimic a thick plant cuticle to provide a barrier to ice nucleation in plants. Hydrophobic kaolin consists of kaolin particles that have been coated with a hydrophobic material. Industrially, this material is added to plastic and rubber compounds to increase water repellency and strength as well as to provide increased electrical insulation. Currently, there are no agricultural uses of hydrophobic kaolin, although other formulations of kaolin particle films have been used for insect control and to alleviate heat stress (Glenn and Puterka, 2004). These formulations are sold under the trade name Surround (NovaSource, Phoenix, AZ).

As reported by Wisniewski et al. (2002a), use of the hydrophobic particle film clearly prevented extrinsic ice nucleation and allowed plants to supercool. For example, tomato plants (Lycopersicon esculentum Mill.) coated with the hydrophobic kaolin supercooled to $-6{ }^{\circ} \mathrm{C}$ compared with uncoated plants, which froze at $\approx-2.5{ }^{\circ} \mathrm{C}$ (Fig. 3). In a field test reported in that study, more than $60 \%$ of the tomato plants coated with the hydrophobic kaolin survived a natural frost event compared with less than 5\% of the uncoated plants. Inversely, over $90 \%$ of the uncoated plants were killed by the frost event compared with $\approx 25 \%$ of the kaolincoated plants. Details of the experiments (freezing rates, plant and air temperature, duration of the freeze, and so on) are provided in the original study (Wisniewski et al., 2002a). The ability to provide frost protection to frost-sensitive plants or plant parts was extended to potato (Solanum tuberosum L.), grape (Vitis vinifera L.), and citrus [Citrus limon (L.) Burm.f.] seedlings (Fuller et al., 2003; unpublished data) as indicated in Figure 4. To be effective, the hydrophobic particle film should be applied within $12 \mathrm{~h}$ before the expected freezing event and reapplied before subsequent frost episodes. Clearly, providing a hydrophobic barrier to the exterior of plants is an effective way to block extrinsic sources of ice nucleation and provide a modicum of frost protection to
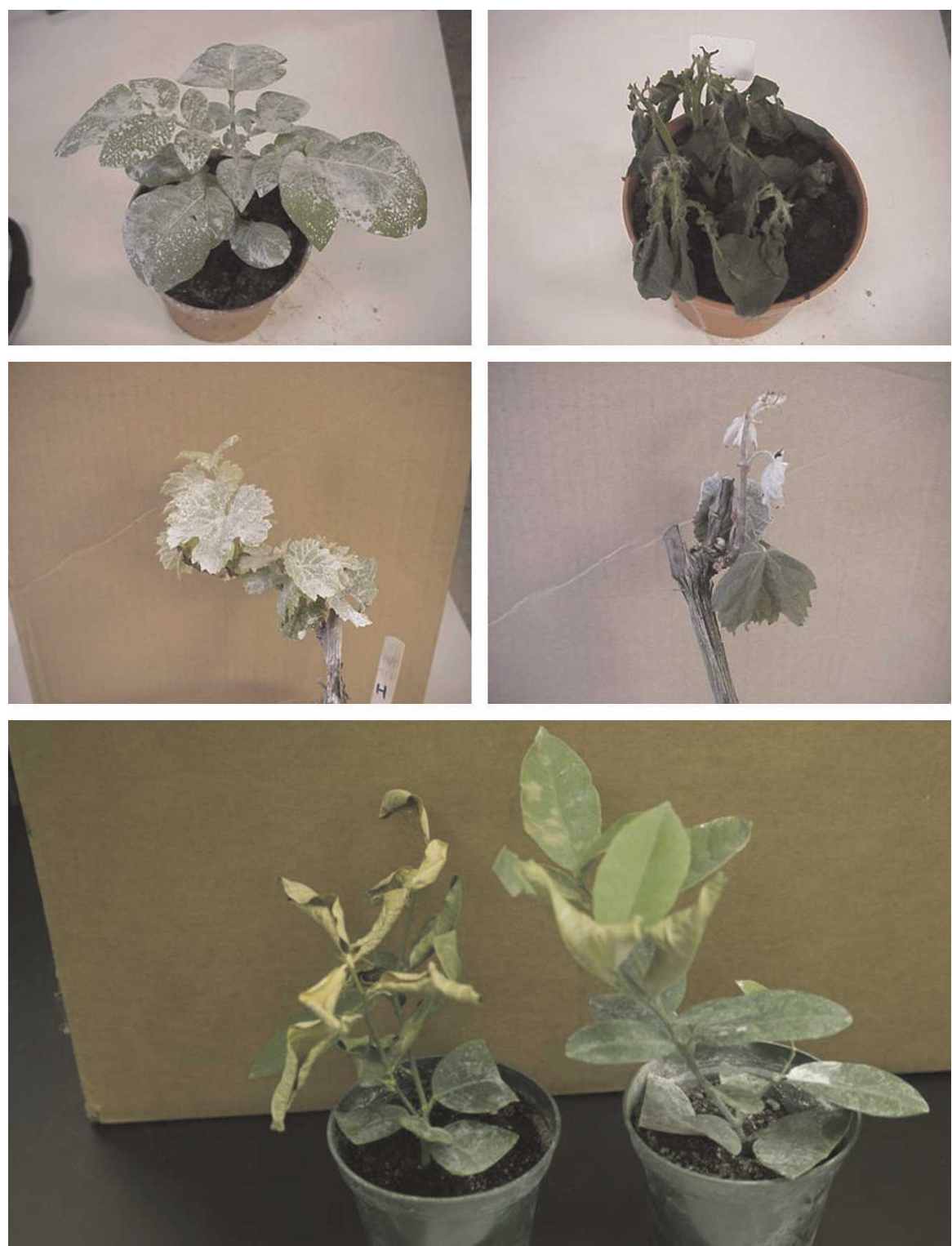

Fig. 4. Frost protection of potato (top), grape (middle), and citrus (bottom) plants coated with a hydrophobic particle film. All plants were subjected to -3 to $-4{ }^{\circ} \mathrm{C}$. Coated plants are on the left in the top and middle frames (potato and grape, respectively) and on the right in the bottom frame (citrus). 
frost-sensitive plants or plant parts (i.e., new growth on perennial plants).

\section{ICE NUCLEATION IN WOODY PLANTS}

In contrast to herbaceous plants, the presence of effective (i.e., active at a warm temperature) intrinsic ice nucleators appears to be common in woody plants. In many cases, the intrinsic ice nucleating agents in woody plants appear to be as effective as extrinsic ice nucleating agents such as INA bacteria and frost crystals. Barriers appear to exist, however, that prevent ice propagation into lateral appendages such as buds or newly extended primary tissues (Carter et al., 2001; Workmaster et al., 1999). These barriers appear to be effective in blocking the propagation of ice into the lateral appendages if ice formation in the stem occurs at a relatively warm, subzero temperature. This allows these appendages to supercool to temperatures well below the freezing temperature of the stems and therefore appears to represent an active mechanism of freeze avoidance. The use of hydrophobic kaolin particle films on woody plants such as grape and citrus indicate that blocking extrinsic nucleation in plants that have intrinsic nucleators may even provide some level of frost protection (Fig. 4).

\section{SUMMARY}

Considerable economic input is used to provide frost protection to plants or parts of plants that have little or no freezing tolerance at the time of the freezing event. Among these efforts are the use of plant or rowcovers, windmills, smudge pots, and the spraying of water on plants through regular or micro- sprinklers. As discussed in other articles in this symposium, understanding the most effective method of frost protection and when to apply it can be quite complex. Very little is known about the mechanisms associated with the freezing of plants under field conditions and this has hampered the development of new, novel, and effective methods of frost protection. The use of high-resolution infrared thermography has clearly provided a wealth of new information on the freezing process in plants and based on these studies, it appears that blocking extrinsic nucleation through the use of a hydrophobic barrier may allow plants or plant parts to supercool and avoid freezing. This represents a novel method of frost protection that warrants further investigation and evaluation of its practical and economic feasibility.

\section{Literature Cited}

Ashworth, E.N. 1992. Formation and spread of ice in plant tissues. Hort. Rev. (Amer. Soc. Hort. Sci.) 13:215-255

Ashworth, E.N. and T.L. Kieft. 1995. Ice nucleation activity associated with plants and fungi, p. 137-162. In: Lee, R.E., Jr., G.J. Warren, and L.V. Gusta (eds.). Biological ice nucleation and its applications. APS Press, St. Paul, MN.

Ball, M.C., J. Wolfe, M. Canny, M. Hofmann, A.B. Nicotra, and D. Hughes. 2002. Space and time dependence of temperature and freezing in evergreen leaves. Funct. Plant Biol. 29:12591272.

Carter, J., R. Brennan, and M. Wisniewski. 2001. Patterns of ice formation and movement in blackcurrant. HortScience 36:1027-1032.

Franks. F. 1985. Biophysics and biochemistry at low temperatures. Cambridge Univ. Press, Cambridge, UK.

Fuller, M.P., F. Hamed, M. Wisniewski, and D.M. Glenn. 2003. Protection of plants from frost using hydrophobic particle film and acrylic polymer. Ann. Appl. Biol. 143:93-97.
Fuller, M.P. and M. Wisniewski. 1998. The use of infrared thermal imaging in the study of ice nucleation and freezing of plants. J. Therm. Biol. 23:81-89.

Glenn, D.M. and G.J. Puterka. 2004. Particle film technology: A new technology for agriculture. In: Janick, J. (ed.). HortReviews 31:1-44.

Hacker, J. and G. Neuner. 2007. Ice propagation in plants visualized at the tissue level by infrared differential thermal analysis (IDTA). Tree Physiol. 27:1661-1670.

Lindow, S.E. 1995. Control of epiphytic icenucleation active bacteria for management of frost injury, p. 239-256. In: Lee R.E., Jr., G.J. Warren, and L.V. Gusta (eds.). Biological ice nucleation and its applications. APS Press, St. Paul, MN.

Wisniewski, M. and M.P. Fuller. 1999. Ice nucleation and deep supercooling in plants: New insights using infrared thermography, p. 105118. In: Margesin, R. and F. Schinner (eds.). Cold-adapted organisms: Ecology, physiology, enzymology, and molecular biology. SpringerVerlag, Berlin, Germany.

Wisniewski, M., D.M. Glenn, and M.P. Fuller. 2002a. Use of a hydrophobic particle film as a barrier to extrinsic ice nucleation in tomato plants. J. Amer. Soc. Hort. Sci. 127:358364.

Wisniewski, M., M. Fuller, D.M. Glenn, L. Gusta, J. Duman, and M. Griffith. 2002b. Extrinsic ice nucleation in plants: What are the factors involved and can they be manipulated? $\mathrm{p}$. 211-221. In: Li, P.H. and E.T. Palva (eds.). Plant cold hardiness: Gene regulation and genetic regulation. Kluwer Academic, New York, NY.

Wisniewski, M., S.E. Lindow, and E.N. Ashworth. 1997. Observations of ice nucleation and propagation in plants using infrared video thermography. Plant Physiol. 113:327-334.

Workmaster, B.A.A., J.P. Palta, and M. Wisniewski. 1999. Ice nucleation and propagation in cranberry uprights and fruit using infrared video thermography. J. Amer. Soc. Hort. Sci. 124: 619-625. 